\title{
Atributos morfológicos configuracionais e copresença em loteamentos residenciais dispersos de cidades médias brasileiras
}

\author{
Filipe Maciel e Fábio Zampieri \\ Universidade Federal de Santa Maria (UFSM), Av. Roraima $n^{\circ} 1000$, Cidade \\ Universitária, Bairro Camobi, Santa Maria - RS, CEP: 97105-900, Brasil. \\ E-mail: filipebassan@gmail.com
}

Artigo revisto recebido a 23 de Abril de 2018

\begin{abstract}
Resumo. $O$ objetivo do trabalho é identificar quais os atributos morfológicos configuracionais de maior correlação com a copresença no contexto sócio-espacial de dois loteamentos residenciais dispersos em Santa Maria (RS), Brasil. Por copresença, entende-se o conjunto de pessoas que estão juntas em determinado espaço. A metodologia é composta por: i) modelagem sintática axial e segmentada da área de estudo com diferentes raios; (ii) coleta da variável copresença categorizada em 'pedestres em movimento' e 'pedestres estacionários'; e iii) cálculo dos coeficientes de correlação de Pearson entre copresença e variáveis sintáticas. Parte-se do seguinte questionamento: como a forma urbana explica a apropriação social dos espaços livres nos loteamentos dispersos? Os resultados mostraram que, embora os dois loteamentos tenham padrões diferenciados de copresença, as variáveis 'integração' e 'escolha' têm as correlações positivas mais fortes com o número de pedestres. Os tipos de modelagem e de raio influenciaram na força das correlações: a análise angular segmentada com raio métrico mostrou-se mais eficiente para o maior número de categorias de copresença quando estas não são compostas essencialmente por movimento natural. Em geral, raios maiores aplicados às medidas locais geraram as correlações mais fortes: R1000m para a análise angular, e R5 para a análise axial.
\end{abstract}

Palavras-chave: copresença, sintaxe espacial, morfologia urbana

\section{Introdução}

A copresença corresponde ao conjunto de pessoas que estão juntas em um espaço, não necessariamente interagindo ativamente entre si (Hillier, 2007). O seu estudo procura entender como o espaço que permeia as pessoas interfere na maneira como elas se movem, param e encontram outras pessoas (Holanda, 2002). Pessoas copresentes são parte da matéria-prima para a criação da comunidade, pois a copresença é a forma primitiva delas tomarem consciência dos demais no espaço compartilhado (Hillier, 2007). Grannis (1998) enfatiza a importância das ruas locais para o potencial de interação do bairro, não apenas entre os vizinhos próximos, mas também entre os mais distantes, a partir das interações face-a-face que ocorrem nas ruas e que permitem que os moradores se reconheçam de vista. Netto et al. (2012) reforçam isso, considerando a copresença um aspecto social anterior às formas de sociabilidade em si, mas que as subjazem. Para Zukin (1995) a copresença permite a experiência do 'outro' em uma situação cotidiana e a formação de uma cultura pública. Ser copresente nas ruas, praças e parques oportuniza obter informações sobre as condições de vida das 
outras pessoas, tornando esses espaços públicos lugares para um constante processo de criação de diferentes solidariedades e identidades de grupo, as quais podem ser integradas na sociedade em geral.

Por sua vez, a dispersão é a característica atual da urbanização brasileira, cujo princípio fundamental é o crescimento territorial acentuado, com descontinuidades ou vazios territoriais (Catalão, 2015). O processo tende a criar enclaves espaciais, resultantes de uma fraca estruturação espacial local que limita a articulação global de cada um deles com o sistema da cidade, não conformando um destino natural para o movimento de pedestres ou de veículos (Hillier, 2007). Logo, tende a diminuir o contato entre moradores de diferentes partes da cidade. O estudo da dispersão é relativamente recente no país, pós-1990 (Reis, 2006) e a quase totalidade das pesquisas tem se concentrado nas zonas metropolitanas (Catalão, 2015; Reis e Bentes, 2016).

Especificamente, os estudos de copresença no Brasil, como os de Arrais (2015), Braga (2003), Netto et al. (2012) e Zampieri (2012) contemplaram principalmente áreas urbanas centrais. As zonas periféricas foram pouco exploradas, especialmente nas cidades médias, aquelas com população entre 100.000 e 500.000 habitantes, e que apresentam as maiores taxas de crescimento médio geométrico do país nos últimos anos (IBGE, 2014), sobretudo pela dispersão do seu território. Aqui, utiliza-se 'cidade média' mais como referência ao seu critério demográfico objetivando situar o contexto analisado em termos de tamanho de sistema sócio-espacial numa classificação pré-existente - do que funcional, em termos do papel exercido pelo assentamento na rede urbana. No entanto, é preciso mencionar que no Brasil existe uma diversidade sócio-espacial bastante ampla que a denominação cidade média não consegue abarcar. Posto isso, considerandose a copresença como um indicador da apropriação social dos espaços públicos, a partir da identificação de seus padrões e de suas relações com as características espaciais, poderão ser inferidos efeitos sociais potenciais do ambiente construído na contemporaneidade.
Uma teoria tem se mostrado relevante em estudos de copresença, a sintaxe espacial, segundo a qual a partir dos atributos configuracionais da forma urbana se identificam padrões espaciais potencialmente correspondentes a padrões de copresença. Esses padrões espaciais podem ser descritos pelas diferentes variáveis obtidas com a análise sintática do espaço, axial ou segmentada, utilizando diferentes restrições de distância (raios) topológica, angular ou métrica aplicadas às análises de escala local, como um loteamento, ou global, como a da cidade. Questiona-se, então, como a forma urbana explica a apropriação social dos espaços livres nos loteamentos dispersos, ou seja, quais as variáveis advindas da sintaxe espacial possuem maior associação com a copresença no contexto considerado?

A hipótese é que as variáveis sintáticas integração e escolha possuiriam maior associação com a copresença, pois ambas capturam centralidades, respectivamente, por proximidade e por intermediação, sendo que a força das correlações dependeria dos tipos de modelagem e raio aplicado às medidas locais. O objetivo aqui, portanto, é identificar as variáveis sintáticas de maior correlação com a copresença no contexto considerado, focando na comparação das diferentes modelagens sintáticas e raios locais. $\mathrm{Na}$ segunda seção serão apresentados os aportes teóricos que embasam o trabalho; seguido pela descrição da metodologia e do objeto empírico de estudos, nas terceira e quarta seções; e finalizando, nas quinta e sexta seções, com os resultados e as conclusões.

\section{Configuração urbana, sintaxe espacial e copresença}

A configuração urbana consiste em uma descrição sistêmica da cidade, ou seja, representa sua realidade espacial através de categorias de elementos e de regras que interligam cada componente a todos os outros do sistema, de modo que uma mudança em qualquer um desses elementos reflete-se em todo o sistema (Krafta, 1997). Essa descrição permite quantificar propriedades particulares do sistema espacial, as quais, no caso da sintaxe espacial, são utilizadas na investigação das 
relações entre sociedade e espaço, a partir de um modelo conceitual com base no conteúdo social dos padrões espaciais e no conteúdo espacial dos comportamentos sociais. A teoria obteve respaldo científico a partir dos resultados de estudos urbanos conduzidos ao redor do globo nas últimas três décadas, divulgados, por exemplo, no periódico The Journal of Space Syntax e nos onze International Space Syntax Symposium realizados até o momento.

Segundo Hillier e Hanson (1984), em um sistema espacial, o acesso e o movimento dos pedestres são controlados pela estrutura de barreiras que delimitam os espaços livres. Esta oportuniza escolhas de rotas para deslocamentos e forma um campo potencial de copresença, estabelecendo uma interface entre o estranho e o morador. Os estranhos a um assentamento ou à parte dele, geralmente, estão de passagem pelo espaço, enquanto que os moradores estabelecem relações mais duradouras e locais, exercendo controle sobre as suas imediações.

$\mathrm{Na}$ modelagem axial, a rede de espaços livres de um assentamento - bidimensional sofre uma simplificação unidimensional, reduzindo-os a unidades de análise chamadas linhas axiais e constituindo o mapa axial. A partir dele, as propriedades espaciais do sistema são mensuradas utilizando como referência a distância topológica e a conexão entre as linhas axiais (Hillier e Hanson, 1984). Já na modelagem segmentada, uma evolução mais recente do método anterior, as linhas axiais são seccionadas, gerando a unidade de análise chamada segmento, definido como a seção de uma linha axial, rua ou caminho que se encontra entre duas interseções. $\mathrm{O}$ mapa segmentado possibilita, então, a análise angular, que parte da ideia central de que o pedestre que se desloca entre dois pontos escolhe uma rota que resulte nas mínimas mudanças de direção possíveis, e nos caminhos mais curtos, contínuos e diretos. Esse é, simplificadamente, o conceito da navegação humana em sistemas espaciais, que vem sendo aplicado na análise do potencial de movimento de pedestres (Hillier e Iida, 2005; Turner, 2001).

$\mathrm{Na}$ análise axial, todas as mudanças de direção existentes no sistema espacial são calculadas com o mesmo peso, quaisquer que sejam os ângulos formados entre as linhas.
$\mathrm{Na}$ análise angular, que leva em conta a navegação humana, as mudanças de direção entre segmentos são ponderadas de acordo com o ângulo em que ocorrem: quando formam um ângulo de 180 graus, o peso atribuído é zero; já quando o ângulo forma 90 graus, é atribuído um peso máximo. No processamento, as mudanças de direção vão sendo computadas, recompensando a maior sequência de linhas retas entre os segmentos (Zampieri, 2012), o que destaca os caminhos com menor desvio angular do sistema, ou seja, aqueles com maior potencial de uso pelos pedestres (Al-Sayed et al., 2014).

A principal variável sintática axial é a integração, que mensura a centralidade por proximidade topológica de uma linha axial em relação a todas as demais do sistema. É uma medida de acessibilidade relativa, que indica potencialmente os níveis de copresença de um dado espaço (Hillier, 2007). A partir da integração Hillier et al. (1993) propuseram um novo paradigma configuracional para a previsão de copresença no espaço urbano: a teoria do movimento natural. Até então, o problema era caracterizado nos termos dos diferentes graus de atratividade dos usos do solo na origem e destino de pedestres, sem considerar possíveis efeitos da configuração espacial urbana. $\mathrm{Na}$ abordagem configuracional, os espaços mais integrados do sistema têm o potencial de serem mais utilizados nos deslocamentos quando comparados aos mais segregados. Assim, a malha urbana opera como geradora primária do movimento de pedestres ao canalizá-lo, independente da existência de atratores: edifícios ou recursos urbanos com o potencial de gerar viagens de e para as formas construídas.

A parcela de copresença potencial gerada apenas pela configuração urbana denominase movimento natural, distinguido entre movimento com destino a um espaço (tomovement), correlacionado à integração, $\mathrm{e}$ movimento de passagem (throughmovement), correlacionado à escolha. Esta segunda variável sintática avalia o grau de confluência de cada linha axial ou segmento nos caminhos mais rápidos ou curtos, topologicamente, metricamente, etc., entre todos os pares de linhas do sistema (Hillier e Vaughan, 2007), ou seja, centralidade por 
intermediação. Linhas axiais ou segmentos com maiores valores de escolha têm maior potencial de serem utilizadas como caminho na escolha de rotas.

Ambas as variáveis axiais, integração e escolha, podem ser calculadas em dois níveis: global e local. No primeiro caso, considera-se o número total de mudanças de direção existente no sistema espacial, não impondo nenhum limite para a análise; já no segundo, restringe-se o cálculo a um determinado raio topológico, depreendendo uma visão localizada. A integração local, sobretudo de raio três, é a melhor maneira de prever o potencial de movimento dos pedestres, que, geralmente, fazem percursos mais curtos (Hillier, 2007), ou seja, deslocam-se com até três mudanças de direção. Raios maiores, como cinco ou sete, tendem a capturar nuances das escalas de movimento não perceptíveis com o raio três, aproximando-se do movimento global. No caso das versões angulares dessas variáveis, suas medidas locais podem ser calculadas com raios angulares, topológicos ou métricos. Estes últimos tornam-se interessantes para aproximar a análise à distância métrica média alcançada pelos deslocamentos dos pedestres, em torno de $500 \mathrm{~m}$ (Gehl, 2013).

Outras variáveis axiais importantes são a 'conectividade' e o 'controle', que contabilizam, respectivamente, o número de conexões diretas de uma determinada linha axial e o grau de controle de acesso exercido por uma linha axial sobre suas vizinhas imediatas, levando em consideração o número de conexões alternativas disponíveis para cada uma delas. Ambas são medidas locais, que indicam a importância de determinados espaços livres na promoção da acessibilidade relativa do sistema. $\mathrm{Na}$ análise angular há ainda as variáveis conectividade, semelhante à versão axial, mas que contabiliza o número de conexões diretas de um determinado segmento e, a 'conectividade angular', que mensura o ângulo cumulativo na mudança de direção entre segmentos conectados. Quanto maior a conectividade angular de um segmento, maior é o desvio angular estabelecido na mudança de direção a partir dele (Al-Sayed et al., 2014). Pelos princípios da navegação humana, os pedestres procurariam realizar seus deslocamentos por caminhos mais retos possíveis, de menor desvio angular. Logo, estas quatro últimas variáveis podem também estar relacionadas à copresença.

Quanto maior a inteligibilidade de um sistema, ou seja, a correlação entre as medidas axiais de integração global e a conectividade, maior a probabilidade de que os fluxos de pedestres estejam concentrados ao longo das linhas mais integradas. Conforme o sistema espacial cresce, a tendência é diminuir a sua inteligibilidade (Hillier et al., 1987), diminuindo, portanto, a correspondência entre movimento potencial e o medido empiricamente. Holanda (2002) coloca que, mesmo em condições de alta inteligibilidade, essa correspondência não é alta. A explicação para isso envolve muitos fatores, podendo dar-se em razão de outros aspectos espaciais, como os próprios atratores. Em zonas cujos usos do solo e densidades construtivas são relativamente bem distribuídos, entre $60 \%$ e $80 \%$ da variação de movimento de local para local pode ser explicada pelos atributos configuracionais por si só (Penn, 2001).

\section{Metodologia}

Foram incluídas no estudo as seguintes variáveis sintáticas, com respectivos raios topológicos e métricos compatíveis com o movimento de pedestres: integração (axial Rn, R3 e R5; angular Rn, R500m e R1000m); escolha (axial Rn, R3 e R5; angular Rn, R500 m e R1000 m); conectividade (axial e angular); controle e conectividade angular. Adotou-se como unidade de análise o segmento, pois esse permite trabalhar com ambas as variáveis sintáticas axiais e angulares: cada segmento recebe o valor da variável axial correspondente à sua linha axial de origem. Foi utilizado o software depthmapX 0.50 para processamento dos mapas axial e segmentado da área de estudo, elaborados pelos próprios autores com dados de 2017.

Atualmente, existem diversas técnicas desenvolvidas para contagem de pedestres, umas mais adequadas do que outras dependendo do propósito da coleta (Vaughan e Grajewski, 2001). Nesta pesquisa, o método da 'contagem em movimento' 
(Hillier et al., 1993) foi escolhido por permitir a contabilização simultânea de pedestres parados e em movimento. Nele, o pesquisador caminha a uma velocidade média aproximada de $1,5 \mathrm{~m} / \mathrm{s}$ ao longo das rotas selecionadas, contando o número de pedestres pelos quais se passa. Apenas são contabilizados os pedestres em movimento (ou seja, que realizam deslocamento por meio do próprio corpo) no sentido contrário ao deslocamento do pesquisador e/ou aqueles que se encontram parados, interagindo ou não com outros pedestres. Essa distinção é feita para diferenciar as apropriações do espaço urbano em movimento de passagem e atividades estacionárias. As rotas observadas foram percorridas pelo pesquisador sempre em um único sentido de deslocamento, partindo-se do mesmo ponto inicial.

Como o espaço urbano pode apresentar variações de copresença momentâneas, não representativas dos níveis rotineiros, é necessária a contagem em vários horários durante o dia e em diferentes dias de semana, obtendo-se uma média dos níveis de copresença, para minimizar erros. Nesta pesquisa, as contagens ocorreram em cinco intervalos de tempo: $8 \mathrm{~h}-10 \mathrm{~h}, 10 \mathrm{~h}-12 \mathrm{~h}, 12 \mathrm{~h}-$ $14 \mathrm{~h}, 14 \mathrm{~h}-16 \mathrm{~h}$ e $16 \mathrm{~h}-18 \mathrm{~h}$, sendo repetidas em quatro dias típicos (terça-feira, quarta-feira ou quinta-feira), conforme Zampieri (2012), mas também em quatro dias atípicos (domingo), nos quais, potencialmente, há menor influência dos atratores comerciais e de serviços sobre o movimento natural. Cada rota foi observada, portanto, 40 vezes. Hillier et al. (1993) ainda recomendam que as observações sejam conduzidas sob as mesmas condições de tempo, porque as atividades estacionárias são afetadas consideravelmente por fatores como temperatura e nebulosidade. As contagens de pedestres ocorreram entre o final do outono e início do inverno. Todas as variáveis foram tabeladas de acordo com o segmento a que fazem referência e normalizados os seus valores entre zero e um antes do cálculo das correlações.

\section{Objeto empírico de estudo}

Hillier et al. (1993) recomendam para aferição empírica da copresença que sejam feitos percursos por rotas com diferentes características morfológicas: no mínimo vinte segmentos, abrangendo integração e segregação. Escolheu-se realizar o estudo de caso em Camobi (Figura 1), bairro de maior extensão territorial $\left(20,35 \mathrm{~km}^{2}\right.$ ou $16,7 \%$ do território urbano) e população absoluta (261.027 habitantes em 2010), conformado fundamentalmente pela dispersão urbana em Santa Maria, RS - cidade de porte médio (ADESM, 2016; IBGE, 2016) no sul do Brasil - adequando-se ao contexto sócioespacial proposto pela pesquisa. Como essa demandaria um grande tempo para as coletas de dados, em função das repetições de contagens de pedestres, julgou-se necessário limitar o estudo a dois loteamentos apenas, que abrangessem diferentes características morfológicas. Partiu-se inicialmente de uma análise global dos loteamentos através da variável angular 'integração global' (Figura 2), classificando os segmentos da cidade com o método Jenks Natural Breaks, que reduz a variação dentro das classes estipuladas, nesse caso três (baixa, média e alta integração global), e maximiza a variância entre elas. Verificou-se que Camobi possui loteamentos residenciais formados quase que totalmente por segmentos de baixa e/ou média integração angular global, sendo os segmentos de alta integração angular global correspondentes apenas às rodovias que cortam o bairro. Assim, foram escolhidos dois loteamentos, um de baixa a média integração angular global; e outro, de média a alta integração angular global, descritos a seguir.

Rota 1 - COHAB Fernando Ferrari: baixa a média integração global, com uso predominante residencial unifamiliar e inteligibilidade fraca $(r=0,29)$.

Rota 2 - Vila Santos Dumont: média a alta integração global, com usos residenciais uni e multifamiliares, comerciais e de serviços, e inteligibilidade fraca $(r=-0,10)$.

Foram selecionados, aleatoriamente, $20 \mathrm{e}$ 24 segmentos nas rotas 1 e 2, respectivamente, abrangendo as quatro classes da variável angular integração local R1000 m (Figura 3). Assim, se obteve diversidade morfológica também à escala local (Figura 4). 


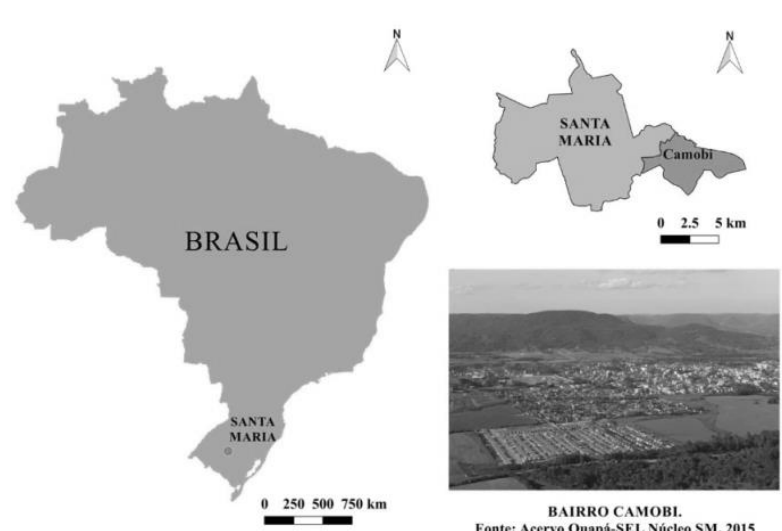

Figura 1. Localização do bairro Camobi.

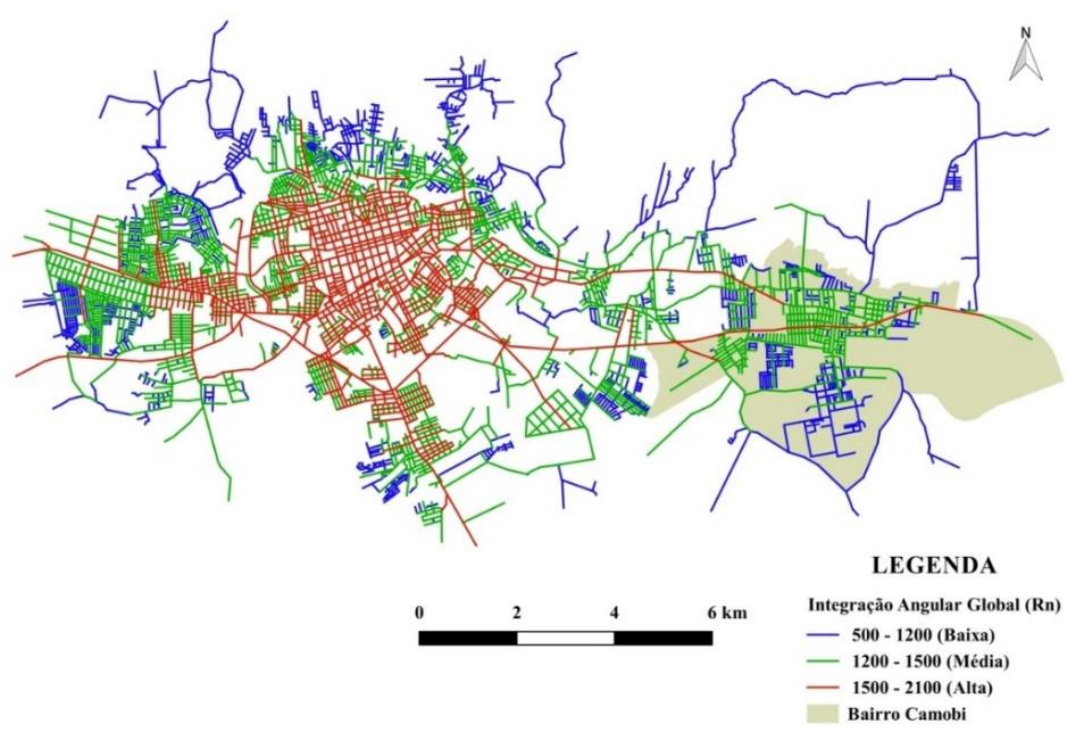

Figura 2. Santa Maria: Integração angular global (Rn).

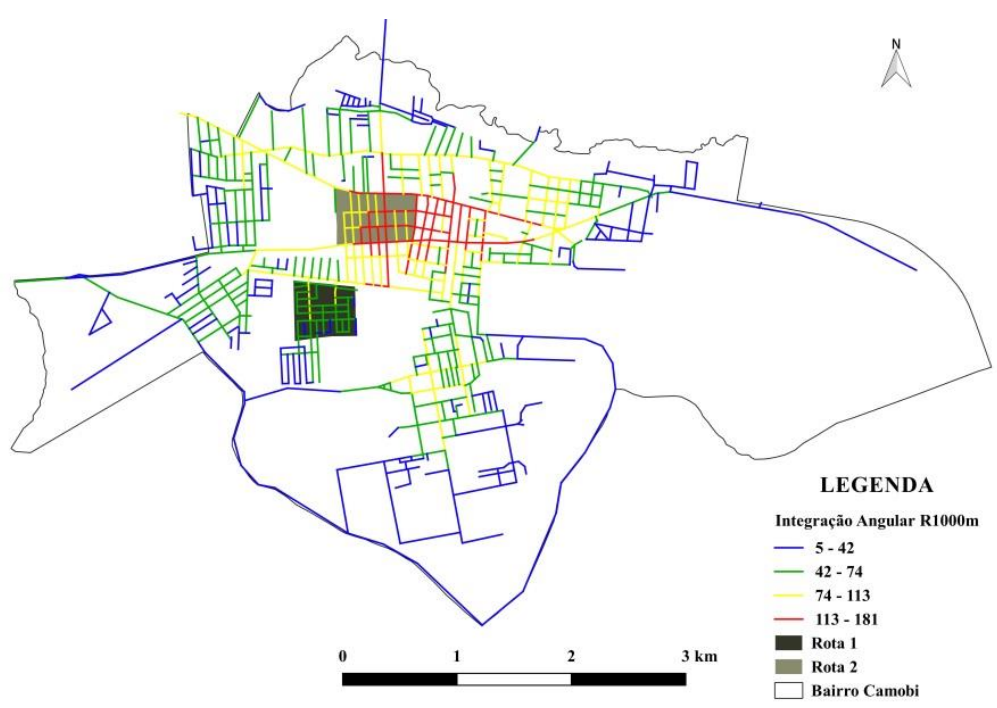

Figura 3. Camobi: Integração angular R1000m. 


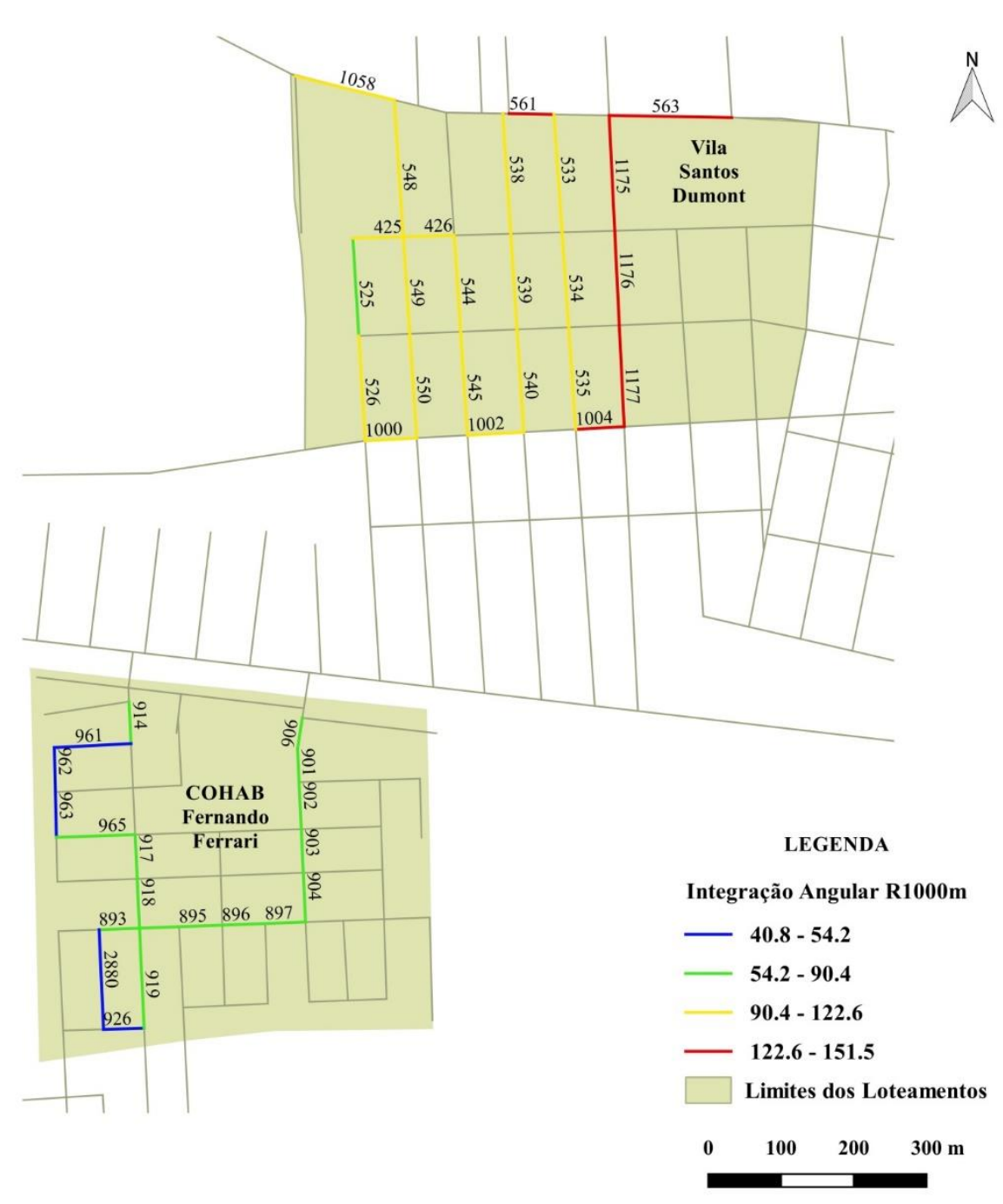

Figura 4. Rotas de estudo: 1. COHAB Fernando Ferrari e 2. Vila Santos Dumont, com indicação dos segmentos selecionados para contagem.

\section{Resultados e discussão}

As correlações (Tabelas 1 e 2) entre a copresença e as variáveis sintáticas foram calculadas primeiramente com os dados das rotas 1 e 2 separados e, posteriormente, em conjunto. Classificaram-se as correlações de acordo com sua força (Dancey e Reidy, 2005) em fracas (valores entre 0,1 e 0,3 ou 0,1 e $-0,3$ ), moderadas (valores entre 0,4 e 0,6 ou $-0,4$ e $-0,6$ ) e fortes (valores entre 0,7 e 1,0 ou $-0,7$ ou $-1,0)$, sendo representadas, respectivamente, a verde, laranja e vermelho.

$\mathrm{Na}$ rota 1, verificaram-se correlações positivas de força fraca a forte entre a copresença e todas as versões da variável integração, confirmando que espaços mais integrados tendem a maiores níveis de copresença. A categoria pedestres parados em dia atípico somente apresentou correlação fraca com a integração axial R3 e a angular R1000 m, medidas locais, sugerindo que os pedestres parados aos domingos são os próprios moradores dos segmentos. A correlação da copresença com ambas as versões globais e locais da integração capturou, além do to-movement vinculado ao domínio de vizinhança, também o movimento de entrada e saída do loteamento essencialmente residencial: seus segmentos mais integrados globalmente fazem a ponte entre o loteamento e a centralidade local, que concentra comércio e serviços. 
Tabela 1. Correlações entre copresença e variáveis sintáticas axiais.

\begin{tabular}{|c|c|c|c|c|c|c|c|c|}
\hline ROTA 1 & $\begin{array}{c}(A x) \\
\text { Integração } \\
\operatorname{Rn}\end{array}$ & $\begin{array}{c}(A x) \\
\text { Integração } \\
\text { R3 }\end{array}$ & $\begin{array}{c}(A x) \\
\text { Integração } \\
\text { R5 }\end{array}$ & $\begin{array}{c}(\text { Ax) } \\
\text { Escolha } \\
\text { Rn }\end{array}$ & $\begin{array}{c}(\text { Ax }) \\
\text { Escolha } \\
\text { R3 }\end{array}$ & $\begin{array}{c}(\text { Ax }) \\
\text { Escolha } \\
\text { R5 }\end{array}$ & $\begin{array}{l}(\mathrm{Ax}) \\
\text { Conecti- } \\
\text { vidade }\end{array}$ & $\begin{array}{c}(\mathrm{Ax}) \\
\text { Controle }\end{array}$ \\
\hline $\begin{array}{l}\text { Parados } \\
\text { (Típico) }\end{array}$ & 0,3 & 0,4 & 0,4 & 0,3 & 0,3 & 0,3 & 0,3 & 0,3 \\
\hline $\begin{array}{l}\text { Parados } \\
\text { (Atípico) }\end{array}$ & 0,0 & 0,1 & 0,0 & 0,2 & 0,3 & 0,2 & 0,3 & 0,2 \\
\hline $\begin{array}{l}\text { Movimento } \\
\text { (Típico) }\end{array}$ & 0,7 & 0,3 & 0,7 & 0,3 & 0,1 & 0,4 & 0,1 & 0,0 \\
\hline $\begin{array}{l}\text { Movimento } \\
\text { (Atípico) }\end{array}$ & 0,6 & 0,6 & 0,7 & 0,8 & 0,6 & 0,8 & 0,6 & 0,5 \\
\hline ROTA 2 & $\begin{array}{c}(A x) \\
\text { Integração } \\
\operatorname{Rn}\end{array}$ & $\begin{array}{c}(A x) \\
\text { Integração } \\
\text { R3 }\end{array}$ & $\begin{array}{c}(\text { Ax }) \\
\text { Integração } \\
\text { R5 }\end{array}$ & $\begin{array}{c}(\mathrm{Ax}) \\
\text { Escolha } \\
\mathrm{Rn}\end{array}$ & $\begin{array}{c}(\text { Ax }) \\
\text { Escolha } \\
\text { R3 }\end{array}$ & $\begin{array}{c}(\text { Ax }) \\
\text { Escolha } \\
\text { R5 }\end{array}$ & $\begin{array}{l}(\mathrm{Ax}) \\
\text { Conecti- } \\
\text { vidade }\end{array}$ & $\begin{array}{c}(\text { Ax) } \\
\text { Controle }\end{array}$ \\
\hline $\begin{array}{l}\text { Parados } \\
\text { (Típico) }\end{array}$ & $-0,3$ & 0,0 & 0,3 & 0,4 & 0,3 & 0,4 & 0,1 & 0,4 \\
\hline $\begin{array}{l}\text { Parados } \\
\text { (Atípico) }\end{array}$ & $-0,3$ & $-0,2$ & 0,1 & 0,2 & 0,0 & 0,2 & $-0,1$ & 0,2 \\
\hline $\begin{array}{l}\text { Movimento } \\
\text { (Típico) }\end{array}$ & $-0,3$ & 0,0 & 0,3 & 0,3 & 0,3 & 0,3 & 0,1 & 0,4 \\
\hline $\begin{array}{l}\text { Movimento } \\
\text { (Atípico) }\end{array}$ & $-0,4$ & $-0,2$ & 0,2 & 0,4 & 0,3 & 0,4 & 0,2 & 0,5 \\
\hline $\begin{array}{l}\text { ROTAS } 1 \\
\quad \text { E } 2\end{array}$ & $\begin{array}{c}(A x) \\
\text { Integração } \\
\operatorname{Rn}\end{array}$ & $\begin{array}{c}(A x) \\
\text { Integração } \\
\text { R3 }\end{array}$ & $\begin{array}{c}(\text { Ax }) \\
\text { Integração } \\
\text { R5 }\end{array}$ & $\begin{array}{c}(\mathrm{Ax}) \\
\text { Escolha } \\
\text { Rn }\end{array}$ & $\begin{array}{c}(\text { Ax }) \\
\text { Escolha } \\
\text { R3 }\end{array}$ & $\begin{array}{c}(\text { Ax }) \\
\text { Escolha } \\
\text { R5 }\end{array}$ & $\begin{array}{l}(\mathrm{Ax}) \\
\text { Conecti- } \\
\text { vidade }\end{array}$ & $\begin{array}{l}(\mathrm{Ax}) \\
\text { Controle }\end{array}$ \\
\hline $\begin{array}{l}\text { Parados } \\
\text { (Típico) }\end{array}$ & 0,2 & 0,2 & 0,3 & 0,4 & 0,3 & 0,4 & 0,2 & 0,1 \\
\hline $\begin{array}{l}\text { Parados } \\
\text { (Atípico) }\end{array}$ & 0,0 & 0,0 & 0,1 & 0,2 & 0,1 & 0,2 & 0,0 & 0,2 \\
\hline $\begin{array}{l}\text { Movimento } \\
\text { (Típico) }\end{array}$ & 0,2 & 0,1 & 0,3 & 0,4 & 0,3 & 0,4 & 0,1 & 0,0 \\
\hline $\begin{array}{l}\text { Movimento } \\
\text { (Atípico) }\end{array}$ & 0,1 & 0,2 & 0,2 & 0,5 & 0,4 & 0,4 & 0,3 & 0,4 \\
\hline
\end{tabular}

Todas as versões da variável escolha mostraram correlações, fracas a fortes, com a copresença na rota 1 , exceto entre a categoria 'pedestres em movimento em dia típico' e a escolha em sua versão angular global, que não se correlacionaram. Todas as correlações foram positivas, exceto entre 'pedestres parados em dia atípico' e 'escolha' angular R500 m, sinalizando que, no domingo, os pedestres parados em um raio de curto alcance são os próprios moradores, que não necessitam buscar segmentos de maior escolha local. Em geral, a copresença tende a aumentar conforme se aumenta o valor de escolha, assim como se verificou com a integração. Para essas duas variáveis, quanto maior o raio utilizado, maiores foram as correlações obtidas: no caso, R5 (axial), R500 m e R1000 m (angulares) apresentaram resultados muito próximos, ou seja, a profundidade desta rota impõe percursos mais distantes, topologicamente ou 
Tabela 2. Correlações entre copresença e variáveis sintáticas angulares.

\begin{tabular}{|c|c|c|c|c|c|c|c|c|}
\hline ROTA 1 & $\begin{array}{l}\text { (Ang) } \\
\text { Integração } \\
\text { Rn }\end{array}$ & $\begin{array}{c}\text { (Ang) } \\
\text { Integração } \\
\text { R500m }\end{array}$ & $\begin{array}{c}\text { (Ang) } \\
\text { Integração } \\
\text { R1000m }\end{array}$ & $\begin{array}{c}\text { (Ang) } \\
\text { Escolha } \\
\text { Rn }\end{array}$ & $\begin{array}{l}\text { (Ang) } \\
\text { Escolha } \\
\text { R500m }\end{array}$ & $\begin{array}{l}\text { (Ang) } \\
\text { Escolha } \\
\text { R1000m }\end{array}$ & $\begin{array}{l}\text { (Ang) } \\
\text { Conecti- } \\
\text { vidade }\end{array}$ & $\begin{array}{l}\text { (Ang) } \\
\text { Conectivi- } \\
\text { dade } \\
\text { Angular }\end{array}$ \\
\hline $\begin{array}{l}\text { Parados } \\
\text { (Típico) }\end{array}$ & 0,4 & 0,4 & 0,4 & 0,3 & 0,5 & 0,4 & 0,5 & 0,3 \\
\hline $\begin{array}{l}\text { Parados } \\
\text { (Atípico) }\end{array}$ & 0,0 & 0,0 & 0,1 & 0,4 & $-0,1$ & 0,1 & 0,1 & 0,1 \\
\hline $\begin{array}{l}\text { Movimento } \\
\text { (Típico) }\end{array}$ & 0,6 & 0,6 & 0,6 & 0,0 & 0,6 & 0,4 & 0,2 & $-0,1$ \\
\hline $\begin{array}{l}\text { Movimento } \\
\text { (Atípico) }\end{array}$ & 0,7 & 0,6 & 0,8 & 0,7 & 0,6 & 0,7 & 0,4 & 0,0 \\
\hline ROTA 2 & $\begin{array}{c}\text { (Ang) } \\
\text { Integração } \\
\text { Rn }\end{array}$ & $\begin{array}{c}\text { (Ang) } \\
\text { Integração } \\
\text { R500m }\end{array}$ & $\begin{array}{l}\text { (Ang) } \\
\text { Integração } \\
\text { R1000m }\end{array}$ & $\begin{array}{c}\text { (Ang) } \\
\text { Escolha } \\
\text { Rn }\end{array}$ & $\begin{array}{l}\text { (Ang) } \\
\text { Escolha } \\
\text { R500m }\end{array}$ & $\begin{array}{l}\text { (Ang) } \\
\text { Escolha } \\
\text { R1000m }\end{array}$ & $\begin{array}{l}\text { (Ang) } \\
\text { Conecti- } \\
\text { vidade }\end{array}$ & $\begin{array}{l}\text { (Ang) } \\
\text { Conectivi- } \\
\text { dade } \\
\text { Angular }\end{array}$ \\
\hline $\begin{array}{l}\text { Parados } \\
\text { (Típico) }\end{array}$ & 0,1 & 0,2 & 0,6 & 0,1 & 0,1 & 0,6 & $-0,1$ & $-0,2$ \\
\hline $\begin{array}{l}\text { Parados } \\
\text { (Atípico) }\end{array}$ & 0,0 & 0,1 & 0,5 & 0,0 & 0,1 & 0,6 & $-0,3$ & $-0,4$ \\
\hline $\begin{array}{l}\text { Movimento } \\
\text { (Típico) }\end{array}$ & 0,0 & 0,2 & 0,7 & 0,1 & 0,1 & 0,6 & $-0,1$ & $-0,2$ \\
\hline $\begin{array}{l}\text { Movimento } \\
\text { (Atípico) }\end{array}$ & 0,2 & 0,2 & 0,6 & 0,3 & 0,2 & 0,7 & $-0,2$ & $-0,4$ \\
\hline $\begin{array}{l}\text { ROTAS } 1 \\
\quad \text { E } 2\end{array}$ & $\begin{array}{l}\text { (Ang) } \\
\text { Integração } \\
\text { Rn }\end{array}$ & $\begin{array}{c}\text { (Ang) } \\
\text { Integração } \\
\text { R500m }\end{array}$ & $\begin{array}{l}\text { (Ang) } \\
\text { Integração } \\
\text { R1000m }\end{array}$ & $\begin{array}{c}\text { (Ang) } \\
\text { Escolha } \\
\text { Rn }\end{array}$ & $\begin{array}{l}\text { (Ang) } \\
\text { Escolha } \\
\text { R500m }\end{array}$ & $\begin{array}{l}\text { (Ang) } \\
\text { Escolha } \\
\text { R1000m }\end{array}$ & $\begin{array}{l}\text { (Ang) } \\
\text { Conecti- } \\
\text { vidade }\end{array}$ & $\begin{array}{l}\text { (Ang) } \\
\text { Conectivi- } \\
\text { dade } \\
\text { Angular }\end{array}$ \\
\hline $\begin{array}{l}\text { Parados } \\
\text { (Típico) }\end{array}$ & 0,3 & 0,2 & 0,4 & 0,2 & 0,0 & 0,3 & 0,1 & 0,0 \\
\hline $\begin{array}{l}\text { Parados } \\
\text { (Atípico) }\end{array}$ & 0,0 & 0,1 & 0,2 & 0,0 & 0,0 & 0,3 & $-0,1$ & $-0,1$ \\
\hline $\begin{array}{l}\text { Movimento } \\
\text { (Típico) }\end{array}$ & 0,2 & 0,2 & 0,5 & 0,1 & 0,0 & 0,3 & 0,0 & 0,0 \\
\hline $\begin{array}{l}\text { Movimento } \\
\text { (Atípico) }\end{array}$ & 0,2 & 0,3 & 0,4 & 0,3 & 0,2 & 0,6 & 0,0 & $-0,2$ \\
\hline
\end{tabular}

metricamente. Embora esse loteamento tenha linhas de baixo potencial de fluxo global, os pedestres que por ele se movimentam dão preferência às rotas mais curtas disponíveis, em termos topológicos e angulares.

Quanto à conectividade, as correlações obtidas entre a copresença e ambas as versões axial e angular da variável foram positivas na rota 1 , indicando que espaços mais conectados tendem a um maior número de pedestres, justamente pela influência desta propriedade na distribuição da acessibilidade e escolha de rota pelo sistema. Pode-se dizer o mesmo da variável controle, de correlações sempre positivas com a copresença, de força fraca a moderada, exceto para 'pedestres em 
movimento em dia típico', que não se correlacionou. A versão angular da variável conectividade, relativa ao segmento, obteve correlações de maior força nos dias típicos e a axial, nos dias atípicos, mas sem considerável diferença. Com a conectividade angular verificaram-se somente correlações de força fraca entre ela e a copresença, exceto para 'pedestres em movimento em dia atípico', em que não houve correlação. Observou-se correlação negativa, mas muito fraca com os 'pedestres em movimento em dia típico', remetendo à tendência da navegação humana de movimentar-se por segmentos com menor desvio angular. Com os 'pedestres parados', essa correlação tornou-se positiva, mas ainda fraca. Isso pode ser coerente quando os pedestres parados nas ruas são os próprios moradores, conhecedores do local, caso da rota 1.

$\mathrm{Na}$ rota 2, observaram-se correlações de força quase sempre fraca ou ausência de correlação entre a copresença e as versões da integração. Assim, sugere-se que aqui o tomovement pode ocorrer em menor proporção ao through-movement ou seu padrão ser mascarado por influência de atratores existentes nas proximidades (comércio, serviços, Universidade e Base Aérea). A única medida de integração que capturou a copresença foi a angular de maior raio métrico (R1000 m), cujas correlações mostraram força média e forte e sinal sempre positivo. Esse raio também foi o que gerou as maiores correlações da copresença com a escolha, embora quase todas as versões dessa variável capturaram a copresença, caracterizando-a fundamentalmente como movimento de passagem. Suas correlações foram sempre positivas e de força fraca a forte.

A variável conectividade mostrou na rota 2 correlações de força fraca com a copresença, sendo quase todas elas positivas e negativas, respectivamente, para as medidas axial e angular. Essa inversão de sinal para as diferentes modelagens, juntamente com a força fraca das correlações, não permitiu um entendimento do comportamento da variável nesta rota. Já o controle manteve correlações semelhantes às da rota 1: sempre positivas, de força fraca a moderada, estabelecendo um padrão de comportamento. Quanto à conectividade angular, suas correlações na rota 2 foram sempre negativas $\mathrm{e}$ de força fraca a moderada, ou seja, o número de pedestres cresce nos segmentos de menor desvio angular nas mudanças de direção. Nesse loteamento, maiores valores de integração e escolha aumentam por si só os níveis de copresença (e também de atratores não residenciais) em relação aos da rota 1. Assim, os pedestres parados nessas ruas mais integradas não são exclusivamente moradores: a eles se agregam 'estranhos', que, para melhor orientação espacial, utilizam caminhos mais retos possíveis.

Quando os dados das duas rotas são analisados em conjunto, o comportamento da maioria das correlações permanece semelhante ao de quando os dados foram processados separadamente: integração, escolha, conectividade (axial) e controle seguem com correlações positivas com a copresença. Quanto à força, a maioria das correlações é fraca, especialmente as da variável integração. Como exceções, tem-se a integração angular de R1000 m e a escolha axial Rn, R5 e angular R1000 m, que alcançam força moderada e tornam-se as variáveis de maior associação com a copresença de forma geral para as duas rotas. Entretanto, também se verificou que nesse processamento em conjunto, dobra o número de ausências de correlação entre categorias de copresença e variáveis sintáticas.

\section{Conclusões}

Esta pesquisa representou uma exploração inicial do estudo da copresença no contexto dos loteamentos residenciais dispersos de cidades médias, limitando-se ao caso de duas áreas distintas apenas. Embora não se possam fazer generalizações, os resultados encontrados podem funcionar mais como um indicativo do caminho metodológico a ser seguido em trabalhos futuros. Cada loteamento apresentou um padrão diferente de copresença: na rota 1 , ele foi capturado por quase todas as variações das medidas de integração e escolha, ou seja, a copresença é constituída basicamente por movimento natural, gerado primordialmente pela configuração urbana. Como o uso do solo predominante na rota é residencial 
unifamiliar, e já consolidado, não ocorre diferenciação espacial considerável em função do atratores. As variáveis configuracionais por si só explicam a copresença nas escalas global e local. A conectividade (axial e angular) e o controle mostraram um padrão claro de comportamento em relação à copresença, influenciando positivamente na distribuição de acessibilidade local. A conectividade angular, mesmo com correlações fracas ou inexistentes, mostrou comportamento coerente com a navegação espacial do morador: o maior conhecimento decorrente de sua relação mais duradoura com o local o dispensa de buscar rotas com menor desvio angular.

As duas rotas já se diferenciaram pelas suas posições relativas na malha da cidade: enquanto a primeira é resguardada dos fluxos do bairro, a segunda configura a centralidade do bairro e é delimitada por duas rodovias, as quais promovem acesso do centro ao bairro e à capital do estado. Esta segunda rota, portanto, está na confluência de fluxos globais, o que se reflete na concentração de atratores comerciais e de serviço, que se beneficiam do movimento de passagem, conjuntamente aos usos residenciais. Por isso, se esperavam correlações moderadas ou fortes da copresença com a variável escolha, previsora do through-movement. Entretanto, as correlações foram quase sempre fracas especialmente as da integração, sugerindo que nesta rota não há somente movimento natural compondo a copresença: os atratores não residenciais modificam sobremaneira a copresença (Hillier et al., 1993) e diminuem suas correlações com os atributos configuracionais.

Uma evidência disso foi a falta de definição do padrão de comportamento para a variável conectividade, cujas versões axial e segmentada geraram correlações fracas, positivas e negativas, respectivamente. $\mathrm{Na}$ rota 1 , as duas versões desta variável apresentaram sempre correlações positivas, sendo algumas moderadas, coerentes com o potencial teórico da variável em aumentar a copresença. As maiores correlações na rota 2 foram obtidas somente com as versões angulares locais das variáveis integração e escolha com R1000 m. Os resultados indicaram que a modelagem segmentada angular com raio métrico tem melhor desempenho do que a axial, para este contexto sócio-espacial. A ponderação angular ajuda a capturar a minúcia da copresença devido à utilização dos princípios da navegação humana na rota 2 , sobretudo pelos estranhos ao assentamento. Sendo menos familiarizados com o local, procurariam se deslocar pelos caminhos com menor desvio angular, ou seja, menor conectividade angular.

As duas premissas da hipótese foram verificadas: analisando-se tanto os dados das rotas separadamente como em conjunto, integração e escolha mostraram-se como as principais previsoras da copresença, com comportamento de correlações quase sempre positivo. O tipos de modelagem e de raio influenciaram a força das correlações, sobretudo no processamento da rota 2 separadamente e nas rotas 1 e 2 em conjunto: a análise angular segmentada com raio métrico mostrou-se mais eficiente para o maior número de categorias de copresença quando estas não são compostas essencialmente por movimento natural. Em geral, raios maiores aplicados às medidas locais geraram as correlações mais fortes: R1000 m para a análise angular, e o R5 para a análise axial. Reforça-se que, quando se trabalha com sintaxe espacial, é necessário utilizar mais de uma versão das variáveis para apreender as diferentes escalas de movimento e a lógica de fluxos da cidade, as quais por si só já informam certas características de cada área.

A respeito da dispersão urbana nas cidades médias e sua relação com a copresença, sabe-se que a inteligibilidade tende a diminuir conforme se aumenta o sistema espacial, e que isso se reflete em menor correspondência entre copresença potencial e a verificada empiricamente. Isso explica as maiores correlações verificadas na rota 1 , de maior inteligibilidade. Ainda assim, as implicações das propriedades configuracionais do sistema espacial foram coerentes, de maneira geral, com a teoria sintática, indo ao encontro e reforçando os resultados de trabalhos em outros contextos.

$\mathrm{Em}$ relação a pesquisas futuras, particularmente no Brasil, há uma grande diversidade de realidades de cidades médias, que necessitam serem exploradas, a fim de 
melhor compreender sua dinâmica sócioespacial. Um ponto a considerar em trabalhos futuros é utilizar algum índice de dispersão urbana para seleção de diferentes áreas de estudo (inclusive com diferentes traçados, não só a grelha ortogonal deste estudo de caso), abordar as mesmas variáveis e verificar se há limites mínimos ou máximos em que essas características passam a ser influentes para a copresença. Outra possibilidade é analisar os dados de copresença agregando pedestres parados e em movimento e verificar as correlações com as variáveis explicativas.

\section{Referências}

ADESM, Agência de Desenvolvimento de Santa Maria (2016) 'Santa Maria em dados' (santamariaemdados.com.br/sociedade/8-6-laz er-e-esporte) consultado em 13 Julho de 2016.

Al-Sayed, K., Turner, A., Hillier, B.; Iida, S. e Penn, A. (2014) Space syntax methodology (UCL, Londres).

Arrais, J. de S. S. (2015) 'Os espaços públicos em áreas centrais: configuração, vitalidade e infraestrutura ociosa no centro antigo de Goiânia', Tese de Mestrado não publicada, Universidade de Brasília, Brasil.

Braga, A. da C. (2003) 'Morfologia, transformação e co-presença em centros urbanos: o caso do Centro do Rio de Janeiro/RJ', Tese de Mestrado não publicada, Universidade Federal do Rio Grande do Sul, Brasil.

Catalão, I. (2015) 'Dispersão urbana: apontamentos para um debate', Cidades 12, 250-77.

Dancey, C. e Reidy, J. (2006) Estatística sem matemática para psicologia: usando SPSS para Windows (Artmed, Porto Alegre).

Gehl, J. (2013) Cidades para pessoas (Perspectiva, São Paulo).

Grannis, R. (1998) 'The importance of trivial streets: residential streets and residential segregation', American Journal of Sociology 103, 1530-64.

Hillier, B. (2007) Space is the machine: a configurational theory of architecture (http://spaceisthemachine.com) consultado em 13 Julho de 2016.

Hillier, B. e Hanson, J. (1984) The social logic of space (Cambridge University Press, Cambridge).

Hillier, B. e Iida, S. (2005) 'Network effects and psychological effects: a theory of urban movement', $5^{\text {th }}$ International Space Syntax Symposium, Delft, 13 a 17 de Junho.

Hillier, B. e Vaughan, L. (2007) 'The city as one thing', Progress in Planning 67, 199-294.

Hillier, B., Burdett, R., Peponis, J. e Penn, A. (1987) 'Creating life: or, does architecture determine anything?', Architecture et Comportement / Architecture and Behaviour 3, 233-50.

Hillier, B., Penn, A., Hanson, J., Grajewski, T. e $\mathrm{Xu}$, J. (1993) 'Natural movement: or, configuration and attraction in urban pedestrian movement', Environment and Planning B 20, 29-66.

Holanda, F. (2002) O espaço de exceção (Universidade de Brasília, Brasília).

IBGE (2014) 'Estimativas da população dos municípios brasileiros com data de referência em $1^{\circ}$ de julho de 2014' (www.ibge.gov.br/home/presidencia/noticias/pd f/analise_estimativas_2014.pdf) consultado em 27 Maio de 2017.

IBGE (2016) 'Sinopse por setores - Censo 2010' (www.censo2010.ibge.gov.br/sinopseporsetores) consultado em 13 Julho de 2016.

Krafta, R. (1997) 'Urban configurational complexity: conceptualization and measurement', $1^{\text {st }}$ International Space Syntax Symposium, Londres, 15 a 18 de Abril.

Netto, V. M., Vargas, J. C. e Saboya, R. T. de (2012) '(Buscando) Os efeitos sociais da morfologia arquitetônica', Urbe 4, 261-82.

Penn, A. (2001) 'Space syntax and spatial cognition: or, why the axial line?', $3^{\text {rd }}$ International Space Syntax Symposium, Atlanta, 7 a 11 de Maio.

Reis, N. G. (2006) Notas sobre urbanização dispersa e novas formas de tecido urbano (Via das Artes, São Paulo).

Reis, N. G. e Bentes, J. C. da G. (2016) 'Urbanização dispersa e novas formas de tecido urbano: estudos, diálogos e desafios', IV Encontro da Associação Nacional de Pesquisa e Pós-graduação em Arquitetura e Urbanismo, Porto Alegre, 25 a 29 de Julho.

Turner, A. (2001) 'Angular Analysis', $3^{\text {rd }}$ International Space Syntax Symposium, Atlanta, 7 a 11 de Maio.

Vaughan, L. e Grajewski, T. (2001) Space syntax observation manual (http://www.neolokator.cz /wp-content/uploads/2017/04/Observation_man ual.pdf) consultado em 10 Janeiro de 2018.

Zampieri, F. L. L. (2012) 'O fenômeno social do movimento de pedestres em centros urbanos', Tese de Doutorado não publicada, Universidade Federal do Rio Grande do Sul, Brasil.

Zukin, S. (1995) The culture of cities (Blackwell, Cambridge). 


\title{
Tradução do título, resumo e palavras-chave
}

Configurational morphological attributes and co-presence in dispersed residential allotments of brazilian medium-sized cities

\begin{abstract}
This paper aims at identifying which configurational morphological attributes have stronger correlation with co-presence in the socio-spatial context of two dispersed residential allotments in Santa Maria (RS), Brazil. Co-presence is the group of people who are together in a given space. The methodology consists of: i) axial and segment analysis of the study area with different radii; ii) measurement of co-presence levels categorized as 'moving pedestrians' and 'stationary pedestrians; and iii) calculation of the Pearson correlation coefficients between co-presence and syntactic measures. It is based on the following question: how does the urban form explain the social appropriation of open spaces in dispersed settlements? The results showed that, although the two neighborhoods have different co-presence patterns, the measures of 'integration' and 'choice' have the strongest positive correlations with the number of pedestrians. The types of analysis and radius influenced the strength of the correlations: segment angular analysis with metric radius was more efficient for the largest number of categories of co-presence when these were not composed essentially by natural movement. In general, larger radii applied to local measurements generated the strongest correlations: R1000m for angular analysis, and $\mathrm{R} 5$ for axial analysis.
\end{abstract}

Keywords: co-presence, space syntax, urban morphology

\section{$8^{\text {a }}$ Conferência da Rede Lusófona de Morfologia Urbana, Maringá, Brasil, 2019}

A $8^{\mathrm{a}}$ conferência da Rede Lusófona de Morfologia Urbana (Portuguese-language Network of Urban Morphology / PNUM) terá lugar na Universidade Estadual de Maringá, no Estado do Paraná, Brasil, de 21 a 23 de Agosto de 2019.

A conferência de 2019 tem como tema 'Forma urbana e natureza', e como subtemas: a ecologia nas cidades, o sistema de espaços livres, a expansão urbana, os padrões morfológicos e, por fim, a história e o património. Um conjunto de questões prementes, e por vezes conflituantes, como a preservação do meio ambiente e a crescente urbanização, a expansão das manchas urbanas e o planeamento ambiental, a qualidade dos espaços urbanos e da vida nas cidades e a ecologia da paisagem serão foco deste encontro do PNUM 2019. A $8^{a}$ Conferência da Rede Lusófona de Morfologia Urbana contará com palestras, mesas-redondas, oficinas, visita técnica, apresentação de trabalhos selecionados e publicação de anais eletrônicos.

A submissão de resumos deverá ser feita entre 3 de Fevereiro e 17 de Março de 2019. O período de inscrição no evento decorre entre 17 de Março e 20 de Julho. Os resultados da avaliação dos resumos serão divulgados a 30 de Abril. A submissão de artigos completos (com carácter opcional) deverá ser feita entre 1 de Maio e 20 de Julho de 2019.

Para mais informações consultar o sítio do evento (https://pnum2019.wixsite.com/maringa), em permanente atualização, ou utilizar o e-mail pnum2019@uem.br. 